\title{
RELACIONAMENTO ENTRE ANFÍBIOS ANUROS E BROMÉLIAS DA RESTINGA DE REGÊNCIA, LINHARES, ESPÍRITO SANTO, BRASIL
}

\author{
José Alberto P. Schineider ${ }^{1}$ \\ Rogério L. Teixeira ${ }^{2}$
}

\begin{abstract}
RELATIONSHIP BETWEEN ANURAN AMPHIBIANS AND BROMELIADS OF THE SANDY COASTAL PLAIN OF REGÊNCIA, LINHARES, ESPÍRITO SANTO, BRAZIL. Some anuran amphibians use the bromeliads during the entire life cycle and others only as diurnal shelter. At the sandy coastal plain of Linhares, State of Espírito Santo, Southeastern Brazil, 676 bromeliads were examined, of which 303 of Aechmea blanchetiana (Baker) L. B. Smith., 1955, 287 of Aechmea nudicaulis (L.) Griseb., 1864, and 86 of Vrisea procera (Mart. Ex Schult. f.) Wittm, 1891. The morphometric and physical-chemical analysis of different bromeliads evidenced variations among plants. During the period sampled, six anuran species were found inside the plant axils. The hylid frog Phyllodytes luteolus (Wied, 1824) was the most abundant species (260 specimens). Its abundance was higher in the epiphyte bromeliad Vrisea procera. Phyllodytes luteolus had higher occurrences in bromeliads located at a transitional area between open and under the shrub vegetation. Specimens of Scinax alterus (Lutz, B., 1973) and Aparasphenodon brunoi Miranda-Ribeiro, 1920, were more frequent mainly in transitional areas; Bufo granulosus Spix, 1824 occurred in open and transitional areas, whereas Gastrotheca fissipis (Boulenger, 1888) and Leptodactylus fuscus (Schneider, 1799) were found only in bromeliads located in open areas.
\end{abstract}

KEYWORDS. Hylidae, Leptodactylidae, Bufonidae, Bromeliad, sandy coastal plain.

\section{INTRODUÇÃO}

A maioria dos estudos sobre comunidades de anfíbios anuros tem se concentrado em ambientes específicos, tais como aquelas espécies que coexistem no chão da floresta, nas margens de rios, lagos ou alagados (Duellman \& Trueb, 1994). Entretanto, as imposições no meio ambiente levam muitos anfíbios a procurarem, principalmente, refúgios em bromélias (Bromeliaceae), exclusivas do continente americano (BENZING, 1990; DejeAn \& Olmsted, 1997). Algumas espécies de anuros se adaptaram de tal maneira às bromélias-tanque, que passaram a utilizar as axilas das plantas durante todo o ciclo de vida, desenvolvendo estratégias avançadas relacionadas com o modo reprodutivo (Duellman, 1985).

Pеixoтo (1995) analisou várias espécies de anfíbios anuros na região sudeste do Brasil que utilizam as bromélias de diferentes maneiras. De acordo com o grau de utilização das plantas pelos anfíbios encontrados, o autor classificou as espécies em dois grupos principais: espécies bromelícolas ou espécies bromelígenas.

A linha costeira brasileira tem uma extensão de $9000 \mathrm{~km}$. Destes, $5000 \mathrm{~km}$ apresentam restingas como um conjunto complexo de ecossistemas, constituídos por uma variedade de vegetação herbácea, arbórea e arbustiva típica que fornece as características peculiares daquele ambiente. Especialmente na orla costeira espíritosantense, as restingas têm sofrido um impacto no que se refere à sua destruição,

1. Curso de Pós-Graduação em Ciências Biológicas, Dep. Biologia, Universidade Federal do Espírito Santo, Av. Marechal Campos, 1468, 29040090, Vitória, Espírito Santo, Brasil.

2. Museu de Biologia Professor Mello Leitão, Av. José Ruschi, 4, Centro, 29650-000, Santa Teresa, Espírito Santo, Brasil. 
principalmente devido à especulação imobiliária. Áreas de restinga fragmentadas podem ser observadas próximas às grandes cidades e nos balneários. Os efeitos mais marcantes sobre a composição da flora e fauna, devido à ação antropogênica, ainda são desconhecidos.

Avaliam-se aqui as espécies de anfíbios anuros que utilizam as bromélias-tanque com diferentes propósitos ecológicos e a ocorrência dos anfíbios em função das diferenças apresentadas por cada microhabitat particular, ou seja, três espécies de bromélias-tanque abundantes na restinga. Foi dada uma ênfase à relação de co-existência da espécie de anfíbio anuro mais abundante (Phyllodytes luteolus Wied, 1824) com as três espécies de bromélias.

\section{MATERIAL E MÉTODOS}

O trabalho de campo foi realizado em uma área de restinga da localidade de Regência, Linhares, norte do

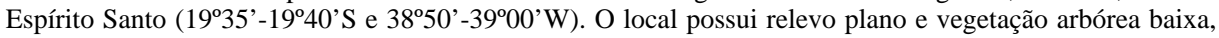
vegetação herbácea e gramíneas, com grande ocorrência de bromeliáceas, distanciando-se da linha de maré cerca de $1000 \mathrm{~m}$. O clima da região é quente e úmido (tipo Aw de Köppen), com estação seca no outono-inverno e estação chuvosa na primavera-verão (PANOso et al., 1978).

As coletas foram efetuadas bimensalmente, entre janeiro e dezembro de 1998, em período diurno (8-17 h). Em cada coleta foram amostradas ao acaso bromélias de três espécies com padrões morfológicos e hábitos diferenciados: Aechmea blachetiana (Baker) L. B. Smith., 1955, Aechmea nudicaulis (L.) Griseb., 1864 e Vrisea procera (Mart. Ex Schult. f.) Wittm, 1891. A cada excursão ao campo, eram escolhidos pontos não levantados anteriormente. Foram analisadas as bromélias terrestres em área aberta (incidência total de luz solar), em área de borda (incidência parcial de luz solar) e em área fechada (pouca ou nenhuma incidência de luz solar direta), bem como as bromélias epífitas (em galhos expostos à luz solar plena). A posição dos exemplares coletados, em relação ao solo, variou de $0,5 \mathrm{~m}$ a mais de $2,5 \mathrm{~m}$.

Cada planta foi seccionada na parte basal e os seguintes parâmetros analisados: as axilas, servindo como potencial reservatório de água, foram contadas; o volume de água foi medido em uma proveta graduada (precisão de $10 \mathrm{ml}$ ); a temperatura da água dentro das axilas foi registrada com um termômetro de mercúrio (precisão de $0,5^{\circ} \mathrm{C}$ ); cada planta foi pesada após a retirada de água em uma balança manual (precisão de $50 \mathrm{~g}$ ) tendo sua altura medida com o auxílio de uma trena $(\mathrm{cm})$. A maioria das bromélias foram replantadas após o procedimento amostral.

Os anuros adultos foram coletados manualmente. Os girinos, após identificados segundo PeiXOTO (1995), foram medidos e devolvidos às bromélias. A captura por unidade de esforço (CPUE) foi utilizada nas análises que envolveram as avaliações do número de exemplares amostrados, de acordo com a espécie ou diferente localização das bromélias, sendo o número de exemplares dividido pelo número de plantas. Espécimens-testemunhos foram depositados na Coleção Zoológica do Museu de Biologia Prof. Mello Leitão (MBML), Santa Teresa e Museu Nacional (MNRJ), Universidade Federal do Rio de Janeiro, Rio de Janeiro.

\section{RESULTADOS}

Foram analisadas 676 bromélias, sendo 303 Aechmea blanchetiana, 287 A. nudicaulis e 86 Vrisea procera. A análise dos parâmetros morfométricos e físico-químicos das espécies de bromélias estudadas, evidenciou variações entre elas (tab. I). Aechmea blanchetiana apresentou maiores médias de volume de água acumulada nas axilas $(535,3$ $\mathrm{ml})$, bem como de peso $(1.501,5 \mathrm{~g})$ e altura $(85,41 \mathrm{~cm})$, obviamente por se tratar da maior bromélia entre as que foram analisadas neste estudo, e o número médio de axilas foi de 18,3. Aechmea nudicaulis, com apenas o tubo central servindo como potencial reservatório, apresentou um baixo volume médio de água (86,4 $\mathrm{ml})$, quando comparada com as outras espécies. Seu peso e altura médios foram de $200,7 \mathrm{~g}$ e $66,1 \mathrm{~cm}$. Vrisea procera apresentou a maior média de axilas $(23,7)$, nas quais se acumulava, em média, $137,4 \mathrm{ml}$ de água. O peso e altura médios foram de $336,1 \mathrm{~g}$ e $35,3 \mathrm{~cm}$. 
Tabela I. Parâmetros morfométricos e físico-químicos das espécies de bromélias estudadas na restinga de Regência, Linhares, ES (N, número de casos; DP, desvio padrão; *, axilas que funcionavam como reservatório de água; **, medida da base à ponta da folha mais alta).

\begin{tabular}{|c|c|c|c|c|c|c|}
\hline \multirow[t]{2}{*}{ Variáveis } & \multicolumn{2}{|c|}{$\begin{array}{l}\text { A. blanchetiana } \\
\mathrm{N}=303\end{array}$} & \multicolumn{2}{|c|}{$\begin{array}{c}\text { A. } \text { nudicaulis } \\
\mathrm{N}=287\end{array}$} & \multicolumn{2}{|c|}{$\begin{array}{c}\text { V.procera } \\
\mathrm{N}=86 \\
\end{array}$} \\
\hline & Média & DP & Média & DP & Média & DP \\
\hline $\mathrm{N}^{\mathrm{o}}$ de axilas $*$ & 18,3 & 5,31 & 1,0 & - & 23,74 & 9,46 \\
\hline Volume de água (ml) & 553,3 & 405,59 & 86,4 & 116,3 & 137,44 & 150,59 \\
\hline Peso $(g)$ & 1501,5 & 771,71 & 200,7 & 103,62 & 336,10 & 250,44 \\
\hline Altura** $(\mathrm{cm})$ & 85,4 & 17,33 & 66,1 & 13,19 & 35,30 & 8,94 \\
\hline Temperatura da água $\left({ }^{\circ} \mathrm{C}\right)$ & 23,8 & 3,10 & 24,2 & 2,40 & 26,70 & 2,50 \\
\hline
\end{tabular}

Durante o período amostrado foram encontradas seis espécies de anfíbios anuros ocupando as bromélias, sendo quatro pertencentes à família Hylidae, um Leptodactylidae e um Bufonidae (tab. II). A espécie Phyllodytes luteolus foi a mais abundante, com 260 indivíduos, seguida por Scinax alterus (8 exemplares) e Aparasphenodon brunoi (7). $\mathrm{Na}$ análise de ocorrência de anfíbios nas três espécies de bromélias estudadas, foi observada uma maior ocorrência de P. luteolus (tab. III). Também esta espécie foi a que apresentou maior índice de captura por planta, sendo maior em $V$. procera, onde foi encontrado quase um indivíduo por planta. As demais espécies de anfíbios apresentaram um baixo índice de captura por planta, não sendo nenhuma delas encontradas em $V$. procera. Das espécies encontradas, apenas $P$. luteolus utiliza as bromélias durante todo o ciclo de vida, enquanto que as demais espécies utilizam as bromélias apenas como refúgio diurno. Um maior número de indivíduos de $P$. luteolus foi capturado nas bromélias localizadas na região de borda $(49,6 \%)$, enquanto que um menor número ocorreu nas bromélias das demais regiões estudadas (tab. IV). Todos os exemplares de S. alterus foram encontrados na região de borda. Aparasphenodon brunoi foi mais representativa na região de borda, embora, tenha também ocorrido na região aberta. Bufo granulosus ocorreu tanto na região de borda quanto na aberta, enquanto Gastrotheca fissipis e Leptodactylus fuscus foram encontrados apenas nas bromélias de borda.

Foram capturados 107 girinos e 260 exemplares adultos de P. luteolus, sendo 64 machos, 122 fêmeas e 74 indeterminados. Foi encontrada uma grande quantidade de ovos dentro de $A$. nudicaulis, a qual possui apenas o tubo central com potencialidade para armazenar água. Em uma planta obtiveram-se 33 ovos e em outra 27, fato ainda não registrado na literatura para $P$. luteolus.

Tabela II. Número de exemplares (N) de anfíbios anuros coletados nas bromélias da restinga de Regência, Linhares, ES, de fevereiro a dezembro de 1998 (CRA em $\mathrm{mm}$ ).

\begin{tabular}{|c|c|c|c|c|}
\hline Famílias / Espécies & $\mathrm{N}$ & $(\%)$ & CRA & $\mathrm{N}^{\text {o. }}$ Lote \\
\hline \multicolumn{5}{|l|}{ Hylidae } \\
\hline Phyllodytes luteolus (Wied, 1824) & 260 & 93,20 & 10,0 a 24,0 & MBML 1322 \\
\hline Scinax alterus (B. Lutz, 1973) & 8 & 2,86 & 22,5 a 28,5 & MNRJ 24806 \\
\hline Aparasphenodon brunoi Miranda-Ribeiro, 1920 & 7 & 2,50 & 47,6 a 74,0 & MNRJ 24807 \\
\hline Gastrotheca fissipis (Boulenger, 1888) & 1 & 0,36 & 59,0 & MBML 1324 \\
\hline \multicolumn{5}{|l|}{ Leptodactylidae } \\
\hline Leptodactylus fuscus (Schneider, 1799) & 1 & 0,36 & 35,5 & MBML 1321 \\
\hline \multicolumn{5}{|l|}{ Bufonidae } \\
\hline Bufo granulosus Spix, 1824 & 2 & 0,72 & 53,0 e 54,0 & MBML 1320 \\
\hline Total & 279 & 100,00 & & \\
\hline
\end{tabular}


Girinos ocorreram em todos os meses amostrados. A abundância destes variou por mês de amostragem e de acordo com a espécie de bromélia (fig. 1). O maior numero de girinos ocorreu na bromélia $A$. nudicaulis ao longo de todo o período amostrado, onde observou-se a presença de até 5 exemplares no tubo central. Nas demais bromélias, a presença dos girinos foi bastante reduzida e não ocorreu em alguns meses. A quantidade de girinos amostrada variou de acordo com a localização das plantas (fig. 2). A grande
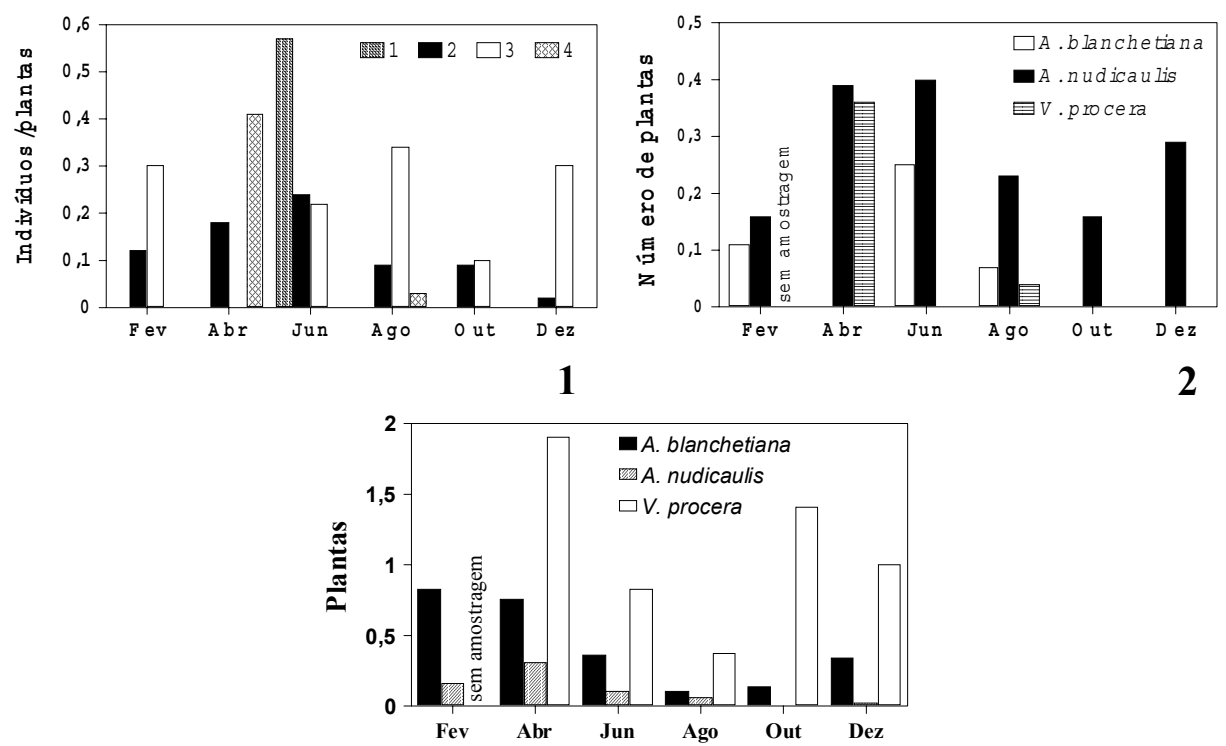

3

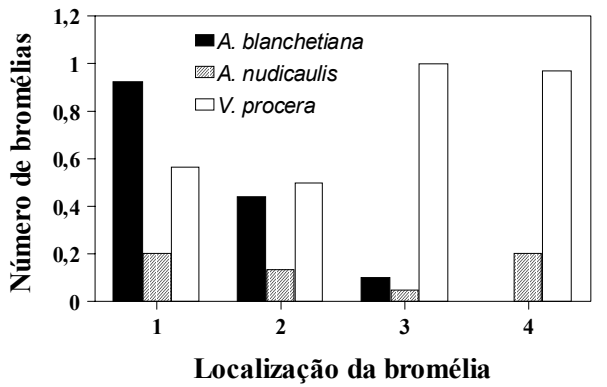

4

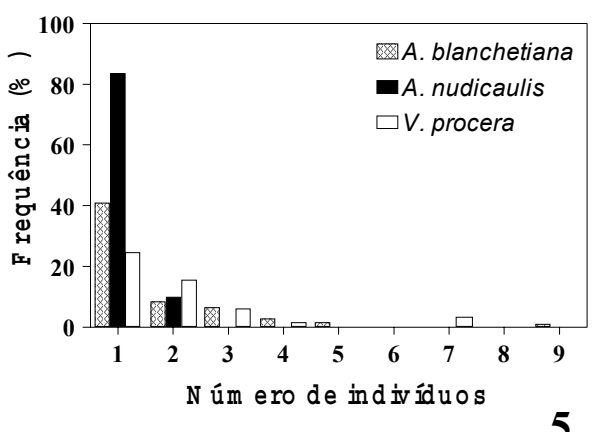

Figs. 1-5. Phyllodytes luteolus nas bromélias da restinga de Regência, ES, de acordo com os meses e locais de amostragens, entre janeiro a dezembro de 1998: 1, número de girinos por planta de acordo com os meses de amostragem; 2 , número de girinos por planta em diferentes locais amostrados; 3 , número de exemplares (juvenis e adultos) por planta de acordo com os meses de amostragem; 4, número de exemplares (juvenis e adultos) por planta em diferentes locais amostrados; 5 , percentual de frequência de ocorrência do número de exemplares (juvenis e adultos) de acordo com as espécies de bromélias. (1, área aberta; 2, área de borda; 3, área fechada; 4, bromélias epífitas). 
Tabela III. Número de exemplares capturados de acordo com o número de plantas analisadas (CPUE, captura por unidade de esforço animal/planta).

\begin{tabular}{|c|c|c|c|c|c|c|}
\hline \multirow{2}{*}{$\begin{array}{l}\text { Família } \\
\text { Espécies }\end{array}$} & \multicolumn{2}{|c|}{ A. blachetiana } & \multicolumn{2}{|c|}{ A. nudicaulis } & \multicolumn{2}{|c|}{ V.procera } \\
\hline & $\mathrm{N}$ & CPUE & $\mathrm{N}$ & CPUE & $\mathrm{N}$ & CPUE \\
\hline \multicolumn{7}{|l|}{ Hylidae } \\
\hline Phyllodytes luteolus & 144 & 0,475 & 31 & 0,108 & 85 & 0,988 \\
\hline Scinax alterus & 5 & 0,016 & 3 & 0,010 & 0 & 0,000 \\
\hline Aparasphenodon brunoi & 6 & 0,019 & 1 & 0,034 & 0 & 0,000 \\
\hline Gastrotheca fissipis & 1 & 0,003 & 0 & 0,000 & 0 & 0,000 \\
\hline \multicolumn{7}{|l|}{ Leptodactylidae } \\
\hline Leptodactylus fuscus & 1 & 0,003 & 0 & 0,000 & 0 & 0,000 \\
\hline \multicolumn{7}{|l|}{ Bufonidae } \\
\hline Bufo granulosus & 2 & 0,006 & 0 & 0,000 & 0 & 0,000 \\
\hline Total & 159 & - & 35 & - & 85 & - \\
\hline
\end{tabular}

Tabela IV. Número de indivíduos capturados de acordo com os locais estudados (N, número de anfíbios; Aberto, bromélias de áreas abertas; Borda, bromélias da área de transição entre áreas abertas e sob as árvores; Fechado, bromélias localizadas sob árvores; Epífitas, bromélias localizadas sobre plantas).

\begin{tabular}{|c|c|c|c|c|c|c|c|c|c|}
\hline \multirow{3}{*}{ Família/Espécies } & \multicolumn{8}{|c|}{ Localização das bromélias } & \multirow{3}{*}{$\begin{array}{r}\text { Total } \\
\mathrm{N}\end{array}$} \\
\hline & \multicolumn{2}{|c|}{ Aberto } & \multicolumn{2}{|c|}{ Borda } & \multicolumn{2}{|c|}{ Fechado } & \multicolumn{2}{|c|}{ Epífitas } & \\
\hline & $\mathrm{N}$ & $\%$ & $\mathrm{~N}$ & $\%$ & $\mathrm{~N}$ & $\%$ & $\mathrm{~N}$ & $\%$ & \\
\hline \multicolumn{10}{|l|}{ Hylidae } \\
\hline Phyllodytes luteolus & 46 & 17,7 & 129 & 49,6 & 10 & 3,8 & 75 & 28,9 & 260 \\
\hline Scinax alterus & 0 & 0,0 & 8 & 100,0 & 0 & 0,0 & 0 & 0,0 & 8 \\
\hline Aparasphenodon brunoi & 2 & 28,6 & 5 & 71,4 & 0 & 0,0 & 0 & 0,0 & 7 \\
\hline Gastrotheca fissipis & 0 & 0,0 & 1 & 100,0 & 0 & 0,0 & 0 & 0,0 & 1 \\
\hline \multicolumn{10}{|l|}{ Leptodactylidae } \\
\hline Leptodactylus fuscus & 0 & 0,0 & 1 & 100,0 & 0 & 0,0 & 0 & 0,0 & 1 \\
\hline \multicolumn{10}{|l|}{ Bufonidae } \\
\hline Bufo granulosus & 1 & 50,0 & 1 & 50,0 & 0 & 0,0 & 0 & 0,0 & 2 \\
\hline
\end{tabular}

maioria dos exemplares ocorreu em plantas localizadas na borda ou sob as árvores, sendo restrita a ocorrência de girinos nas bromélias localizadas em áreas abertas e/ou bromélias epífitas.

Adultos de P. luteolus ocorreram em 86 (28,4\%) de 303 A. blanchetiana examinadas, em $28(9,7 \%)$ de 287 A. nudicaulis e em $42(48,8 \%)$ de 86 V. procera. Em $A$. blanchetiana, o máximo de indivíduos encontrados em uma planta foi 9 . Apenas um indivíduo por planta representou $41,0 \%$ das observações, enquanto que dois indivíduos representaram 8,33\% dos casos. Em A. nudicaulis, apenas um indivíduo ocorreu em $83,9 \%$ dos casos, enquanto que dois indivíduos ocorreram em 12,9\% das observações. Para $V$. procera, observou-se um máximo de sete exemplares em única planta. Entretanto, um indivíduo ocorreu em $24,7 \%$ das observações, enquanto que dois indivíduos ocorreram em $15,3 \%$.

Adultos, juvenis e recém-metamorfoseados de Phyllodytes luteolus ocorreram durante todo o ano (fig. 3). De acordo com os resultados, observou-se uma maior preferência de $P$. luteolus pela bromélia epífita $V$. procera. Houve grande variação na ocorrência de $P$. luteolus de acordo com a localização das bromélias (fig. 4). Em $A$. blanchetiana, o maior número de exemplares foi observado nas bromélias localizadas em áreas abertas, seguido por aquelas plantas localizadas na região de borda. Em $A$. nudicaulis, a maior abundância de $P$. luteolus foi observada nas plantas localizadas em áreas abertas, assim como para aquelas epífitas. Em V. procera, o maior número de 
exemplares foi igualmente observado nas plantas que estavam cobertas pela vegetação e aquelas epífitas. Embora a freqüência tenha variado de 1 a 9 indivíduos por planta, a ocorrência de apenas um indivíduo foi mais constante (fig. 5).

\section{DISCUSSÃO}

Algumas restingas do litoral do Espírito Santo podem apresentar mais de 20 espécies de Bromeliaceae. Entretanto, a maioria tem pouca ou nenhuma capacidade de armazenar água e muitas são de baixa ocorrência, não representando locais relevantes para a colonização dos anfíbios. As principais bromélias-tanque que ocorrem na restinga de Regência diferem nos aspectos morfológicos, e assim, fornecem diferentes oportunidades para serem colonizadas. Aechmea blanchetiana é a que oferece maior espaço e tem a capacidade de acumular um maior volume de água quando comparada com $A$. nudicaulis e $V$. procera. Entretanto, por ser maior, $A$. blanchetiana também deve oferecer mais espaço para os predadores dos anfíbios anuros. Este estudo indica que apenas a capacidade de oferecer mais espaço e mais volume de água não representam os fatores preponderantes para a colonização pelos anfíbios anuros.

Em termos de comunidade, foi observada uma baixa diversidade de espécies de anuros nas bromélias da restinga de Regência. O número registrado foi maior do que para as bromélias da restinga de Guriri, mais ao norte do Espírito Santo, onde ocorreu apenas $P$. luteolus nas bromélias examinadas (TeIXEIRA et al., 1997). Em uma restinga do Rio de Janeiro, Oliveira et al. (1994) encontraram S. alterus e Xenohyla truncata (Izecksohn, 1959) na bromélia-tanque Neoregelia cruenta (R. Grahan) L.B. Smith., 1934. Na região de mata Atlântica, foram registradas 6 espécies de anuros dentro da bromélia de encosta Alcantharea sp.: Thoropa miliaris (Spix, 1824), Scinax alterus, Scinax sp., Hyla faber Wied-Neuwied, 1821, Phyllodytes luteolus e Scinax argireornatus (Miranda-Ribeiro, 1926) (Schineider et al., 2000). Реixoto (1995) citou cerca de 16 espécies de anfíbios que utilizaram bromélias, sendo a maioria apenas como visitantes diurnos. Esses estudos, desenvolvidos em uma diversidade de ecossistemas, têm evidenciado um número maior de espécies de anfíbios que utilizam, mesmo que eventualmente, as bromélias como abrigo. Nota-se que as espécies de bromélias mais relevantes em termos de ocorrência diferem nas várias restingas, assim como as principais estratégias reprodutivas dos anuros em um gradiente latitudinal, embora as restingas representem um conjunto de ecossistemas praticamente contínuo no litoral brasileiro.

Entre as espécies de anfíbios anuros capturadas na restinga de Regência, apenas P. luteolus necessita intrinsicamente do microhabitat oferecido pelas axilas das bromélias para garantir o sucesso reprodutivo. Aparasphenodon brunoi é outra espécie intimamente adaptada à vida dentro das bromélias. Contudo, não desova dentro das bromélias e pode ocorrer em ocos de bambu na região de mata Atlântica. Scinax alterus é uma espécie que ocupa uma diversidade grande de microhabitats, sendo muito comum em lagoas costeiras do Espírito Santo. Gastrotheca fissipes mantém ovos em uma bolsa dorsal (Регхото, 1995) e, aparentemente, não é uma espécie abundante na maioria dos ambientes em que foi encontrada. Bufo granulosus é uma espécie altamente sedentária (TEIXEIRA et al., 1999), passando o período diurno em buracos escavados na areia da restinga, saindo durante a noite para se alimentar, sendo que sua presença em bromélias pode ser considerada acidental. Leptodactylus fuscus constrói tocas próximo a lagoas, onde ocorre 
o amplexo e a deposição de ovos em espuma (Martins, 1988). Sua ocorrência em bromélias também pode ser considerada acidental.

A morfologia das bromélias pode, aparentemente, levar a diferentes interpretações sobre aquela que poderia oferecer um ambiente mais relevante para os anfíbios. $\mathrm{Na}$ restinga de Regência, o maior número de exemplares de $P$. luteolus adultos ou jovens ocorreu na bromélia epífita $V$. procera. Como $A$. blanchetiana é a maior bromélia, poderia oferecer maior microhabitat, assim como garantir um maior suprimento de água para a deposição de ovos. Entretanto, P. luteolus prefere a bromélia menor, e justamente a que acumula menos água. ETEROVIcK (1999) observou que P. luteolus usa mais frequentemente as bromélias epífitas. É provável que estas bromélias possam oferecer um melhor abrigo no que se refere às defesas naturais contra os predadores diurnos.

BoKERMANN (1966) citou que fêmeas de P. luteolus põem normalmente de dois a três ovos por planta. GiaretTA (1996) citou que existe uma tendência das fêmeas de $P$. luteolus em colocar apenas um ovo por axila, sendo uma adaptação relevante para minimizar a competição por alimento e espaço dos girinos. Em duas plantas $(A$. nudicaulis) foi encontrado um número muito alto de ovos, sugerindo que a estratégia de desova possa diferir muito em relação ao que é conhecido ou sugerido até o presente momento. Como o número de exemplares não é alto na restinga de Regência, seria improvável que várias fêmeas tivessem depositado pequenas quantidades de ovos simultâneamente ou mesmo durante a noite, coincidentemente em apenas uma axila de A. nudicaulis. Com relação aos girinos, estes foram, coincidentemente, mais abundantes em A. nudicaulis, a qual tem apenas no tubo central espaço para armazenar água. Os resultados evidenciam que, até certo ponto, $V$. procera é o principal local de abrigo, enquanto que $A$. nudicaulis é o principal local de desova.

As espécies de anfíbios que utilizam as bromélias em diferentes restingas (e.g., Oliveira et al.,1994; Peixoto, 1995; Teixeira et al., 1997) certamente o fazem de maneira diferente. Muitas particularidades restritas aos hábitos das espécies de anuros ainda estão para serem determinadas. Outros estudos abordando localidades em diferentes latitudes ao longo da orla costeira brasileira, especialmente no nordeste brasileiro, poderão evidenciar mais claramente o papel de diferentes espécies de anfíbios em seu ambiente particular. Um maior conhecimento sobre as várias espécies de bromélias, a capacidade de cada uma no que se refere à retenção de água, poderá também elucidar novos fatos que levarão a um maior entendimento sobre a relação anfíbios/plantas.

Agradecimentos. A José Manoel Gomes (Universidade Federal do Espírito Santo) pela identificação das bromélias e José Pombal Jr. (MNRJ) pela confirmação das espécies de anfíbios. A Jesuel F. Bernabé e Gladstone I. Almeida pelo auxílio nos trabalhos de campo. Oswaldo Luiz Peixoto (Universidade Federal Rural do Rio de Janeiro) e um revisor anônimo forneceram excelentes sugestões para a melhora do manuscrito. Este trabalho foi parcialmente financiado pelo CNPq (Projeto "Biodiversidade da Mata Atlântica no Estado do Espírito Santo", Proc. No. 469321/2000-8).

\section{REFERÊNCIAS BIBLIOGRÁFICAS}

Benzing, D.H. 1990. Vascular Epiphytes. New York, Cambridge University. 354 p.

Bokermann, W.C.A. 1966. O gênero Phyllodytes Wagler, 1830 (Anura, Hylidae). Anais Acad. bras. Ciênc., Rio de Janeiro, 38:335-344.

DeJEAn, A. \& Olmsted, I. 1997. Ecological studies on Aechmea bracteata (Swartz) (Bromeliaceae). J. nat. Hist., London, 31(9): 1313-1334.

Duellman, W.E. 1985. Reproductive modes in anuran amphibians: phylogenetic significance of adaptive 
strategies. S. Afr. J. Sci., Pretoria, 81:174-178.

Duellman, W.E. \& Trueb, L. 1994. Biology of Amphibians. New York, McGraw-Hill. 670 p.

Eterovick, P.C. 1999. Use and sharing of calling and retreat sites by Phyllodytes luteolus in modified environment. J. Herpetol., St. Louis, 33(1):17-22.

Giaretta, A.A. 1996. Reproductive specializations of the bromeliad hylid frog Phyllodytes luteolus. J. Herpetol., St. Louis, 30(1):96-97.

MARTins, M. 1988. Biologia reprodutiva de Leptodactylus fuscus em Boa Vista, Roraima (Amphibia: Anura). Revta bras. Biol., Campinas, 48(4):969-977.

Oliveira, M.G.N.; Rocha, C.F.D. \& Bagnall, T. 1994. The animal community associated with the tank bromeliad Neoregelia cruenta (R. Graham) L. B. Smith. Bromélia, Rio de Janeiro, 1(1):22-29.

Panoso, L. A.; Gomes, I. A. et al. 1978. Levantamento de reconhecimento dos solos do Estado do Espírito Santo. Bolm Téc. Embrapa, Rio de Janeiro, 45:1-461.

Peiхото, O. L. 1995. Associação de anuros a bromeliáceas na mata Atlântica. Revta. Univ. Rural, Sér. Ciênc. da Vida, Seropédica, 17(2):75-83.

SCHineider, J.A.P.; TeixeIRA, R.L. \& AlmeidA, G.I. 2000. Aspectos de comunidades de anfíbios bromelícolas em região de Mata Atlântica do Espírito Santo, sudeste do Brasil. Revta Nord. Zool., Ilhéus, 2 (1): 57-62.

Teixeira, R.L.; Zamprogno, C. et al. 1997. Tópicos ecológicos de Phyllodytes luteolus (Amphibia, Hylidae) da restinga de Guriri, São Mateus-ES. Revta bras. Biol., Campinas, 57(4):647-654.

TeixeIRA, R.L.; Schineider, J.A.P. \& Giovanelli, M. 1999. Diet of the toad Bufo granulosus (Amphibia, Bufonidae) from sandy coastal plain in southeastern Brazil. Bolm Mus. Biol. Prof. Mello Leitão, (N. Sér.), Santa Teresa, 10:29-31. 